\title{
Reframing workplace inclusion through the lens of universal design: Considerations for vocational rehabilitation professionals in the wake of COVID-19
}

Kathleen Sheppard-Jones ${ }^{\mathrm{a}, *}$, Penina Goldstein ${ }^{\mathrm{a}}$, Mykal Leslie ${ }^{\mathrm{b}}$, Patti Singleton ${ }^{\mathrm{a}}$, Caroline Gooden ${ }^{\mathrm{a}}$, Phillip Rumrill ${ }^{\mathrm{a}}$, Lindsey Mullis ${ }^{\mathrm{a}}$ and Christina Espinosa Bard ${ }^{\mathrm{a}}$

${ }^{a}$ University of Kentucky, Lexington, KY, USA

${ }^{\mathrm{b}}$ Kent State University, Kent, $\mathrm{OH}, \mathrm{USA}$

Received 4 April 2020

Accepted 15 August 2020

\begin{abstract}
.
BACKGROUND: The experience of disability and of how work is conducted in the American economy is undergoing new shifts in response to the coronavirus (COVID-19) pandemic. This unique space in time provides an opportunity to re-examine the importance of universal design (UD) as a way to respond to a workforce that is growing more diverse and living longer with disabilities. UD is a set of strategies that creates places and resources that are accessible to all and considers the needs and wants of people from the outset. Through the use of UD, work environments can be more accessible and useable to all employees.

OBJECTIVE: This article describes the changes in the experience of disability within the context of COVID-19 and defines UD and UD for learning principles. We then consider how UD reduces stigma and reduces the need for individual accommodations while promoting inclusivity and improving productivity in the workplace.

CONCLUSION: We offer strategies for embedding UD into vocational rehabilitation from pre-professional training to practice, all with a new sense of urgency and opportunity that is present as a result of COVID-19.
\end{abstract}

Keywords: Workplace inclusion, universal design, COVID-19

\section{Introduction}

Our society's value on employment is well understood. When meeting someone, one of the first questions that we want to know is, 'What do you do?'. The socially appropriate response for adults is expected to include information about that person's occupation. In the United States, and in most developed

\footnotetext{
*Address for correspondence: Kathleen Sheppard-Jones, Ph.D., C.R.C., University of Kentucky, 113 Mineral Industries Building, Human Development Institute, Lexington, KY, 40506-0051, USA. Tel.: +1 859257 8104; E-mail: kjone@uky.edu.
}

countries, individuals' identities are largely shaped by their employment roles. This is not surprising, because we consider work to be a critically important pursuit (Zunker, 2015), and the role of employee is one that our culture highly values (Osburn, 2007). Though people are driven by a variety of motivations to engage in work, there is one common theme - there is a societal expectation that individuals of working age will, in fact, work. When students exit high school, they are expected to have a job or seek ongoing education or training to ultimately obtain a job. Employment is the gold standard upon which we largely judge a person's worth. 
However, the COVID-19 pandemic is shifting the 2020 work dialogue in the United States and around the world. The spread of the coronavirus and the attendant global crisis resulted in the effective shut down of US and world economies. Unemployment claims soared to historic levels throughout the spring of 2020 as business and industry largely ground to a halt in the worldwide effort to slow the deadly and highly contagious virus. COVID-19 has led to new challenges and also opportunities around employment and how work is accomplished. For those who have been able to remain employed, much of their vocational and professional interactions are happening in new ways, as organizations shift to remote work and social distancing. As such, it is critical that the voices of people with disabilities be included in all aspects of the conversation to help shape the future of employment. Though not a new idea, the concept of universal design (UD) does provide vocational rehabilitation and other fields invested in social justice with a new way to approach equal access to employment and access to all domains of meaningful societal participation, from education, health care, community participation and independent living.

\subsection{The experience of disability}

More Americans than ever before are living with a variety of physical and mental impairments. The Centers for Disease Control and Prevention (CDC, 2019) estimate that 61 million American adults (26.4\%) currently live with disability. Although this prevalence rate constitutes over one-quarter of the US population, the percentage of people with disabilities in the United States is expected to double in less than 20 years (National Governors Association, 2013). The continued increase in overall prevalence of disability and the emergence of specific conditions in the US is linked with a myriad of social and health related factors. For example, life expectancy increases over the past several decades can be attributed to lower infant mortality rates and advances in healthcare, including medical advancements, new technology, and prescription medications that allow individuals to survive and manage chronic conditions (e.g., heart disease, diabetes, and cancer) for longer periods of time. Furthermore, these medical and technological advances also enable individuals with life-threatening injuries and conditions (e.g., traumatic brain injury, spinal cord injury, stroke) to survive and recover at much higher rates (Cichy et al., 2017). As such, the increase in life expectancy, com- bined with population factors, such as the aging of the 73 million members of the "Baby Boom" generation, is expected to double the number of Americans who are aged 65 and older in the next 30 years, meaning that more Americans will be living long enough to acquire age-related disabilities. By age 60 , it is estimated that one in four people in the US can expect to have a disability, further increasing to around half of all Americans by age 80 , and more than three-quarters at age 90 (Cichy et al., 2017).

In addition, several disabilities have seen increasing prevalence rates across the general population or in specific population segments (e.g., asthma, traumatic brain injury, autism spectrum disorder, multiple sclerosis, rheumatoid arthritis, multiple chemical sensitivity, type 2 diabetes; Baio et al., 2018; Koch $\&$ Rumrill, 2017). The onset of many of these conditions is strongly linked with systemic inequalities that disproportionately affect individuals based on a combination of their individual characteristics, such as gender, race, ethnicity, age, and socioeconomic status. Whether as a precursor to disability or as a result of a disabling condition, these systemic inequalities (e.g., lack of access to healthcare, poor nutrition, housing issues, violence, exposure to environmental hazards) are further exacerbating negative health outcomes for Americans with disabilities, and in some cases are causing secondary conditions (e.g., diabetes leading to visual impairment or amputation, or a chronic pain condition resulting in an opioid use disorder; Koch \& Rumrill, 2017; Leslie et al., in press).

In addition, there are other emerging disabilities, such as opioid use disorder (OUD), that have implications not only for the current generation, but the next. It is estimated that roughly ten percent of all people who use an opioid will develop an OUD (NIDA, 2018). Babies who are born to mothers with OUD subsequently experience neonatal abstinence syndrome (NAS), the ramifications of which are just starting to be fully understood. As these children grow, they will need early childhood interventions and subsequent educational and social supports to succeed in school and later in the workplace (Fill et al., 2018). As such, the CDC has described the national situation as an epidemic (CDC, 2017), with huge investments being made at state and local levels in responses that enforce, deter, treat, and promote the recovery of people with OUD (Substance Abuse and Mental Health Services Administration, 2015).

For all of these reasons, the experience of disability in the United States is changing. As a result, 
there is increasing recognition of disability as a demographic variable instead of an outcome. As the rates of Americans living with disability continue to rise, it is apparent that disability impacts everyone. Most people will likely now live long enough to experience an impairment that, historically, would not have been present prior to their death. Therefore, considering broad strategies to approach accessibility for all can lead to improved opportunities in employment across the lifespan.

\subsection{Universal design}

Universal design (UD) is design that is usable by all people, to the greatest extent possible, without the need for adaptation or specialized measures (Story et al., 1998). UD began as a way to incorporate design elements into architecture that would create physical spaces accessible to a diverse set of users (Story et al., 1998). It uses the framework of human factors design, which is design that accommodates the widest possible range of bodies. This idea benefits all people, and particularly people with disabilities. The strategies employed by UD are practical and cross domains (Center for Universal Design, 1997). As a result, UD has been further recognized as a systematic approach to make products, resources, communications and environments (both in the built and virtual world) that are usable by the widest-possible array of people. UD is the idea that we can build environments and systems that make our communities more accessible for everyone as the starting point, rather than having to continuously make modifications in order to enable a specific individual, who has been selected for inclusion, to begin participating.

The UD definition can serve as a response to the World Health Organization definition of disability related to participation restrictions. Within an employment context, the degree of UD that is created in an environment depends on the degree to which it accommodates the widest array of employees and potential employees possible. Universal design concepts dovetail with Healthy People 2020's goal of creating environments that promote good health for all and are particularly practical to adopt in the work environment. Table 1 includes the seven guiding principles for UD.

Implementing UD principles across physical environments, infrastructures and communications is critical to maximizing the potential of all people (World Health Organization, 2011). The principles of UD that took root to address accessibility of physical spaces have been further extended to include information sharing. As an example, if the physical structure of a library has an accessible entrance, but the library's website content is not compatible with screen readers, the library is not accessible to all. Likewise, if a description of a library resource is written at a 12th grade reading level, that information is only accessible to a subset of people. To truly engage and include all people across environments and within programs, the design of content must also be taken into consideration. Springing from UD and known as universal design for learning (UDL), or universal design for instruction, the principles recognize the process orientation for learning (Burgstahler, 2009) and the reciprocal and effective flow of communication and understanding between people. Principles of UDL are included in Table 2.

Just as UD principles benefit the broadest array of people in the built environment, so too does UDL benefit the widest spectrum of people in the way that information is conveyed. UDL provides a framework for flexibility, for reducing barriers, and for thoughtful design at the outset. Though the term universal design for learning might imply that its place is in

Table 1

Guiding principles of Universal Design

\begin{tabular}{ll}
\hline Principle & Description \\
\hline $\begin{array}{l}\text { 1. Equitable use } \\
\text { 2. Flexible use }\end{array}$ & $\begin{array}{c}\text { The design is appealing to all and avoids stigmatizing people. } \\
\text { The design provides options in methods of use. It is adaptable to the user and } \\
\text { can be used at the pace of the user. The design allows for accuracy. } \\
\text { The design is easy to use regardless of previous experience. The design } \\
\text { accommodates all language abilities. }\end{array}$ \\
$\begin{array}{l}\text { The design presents necessary information using images, speech, or tactile guidance. } \\
\text { 5. Perceptible information } \\
\text { The design minimizes risk and warns of hazards or errors while providing. } \\
\text { features that promote safety }\end{array}$ \\
$\begin{array}{l}\text { The design allows for use with minimal fatigue. The user can remain in a body neutral } \\
\text { position and does not need to repeat an action multiple times. }\end{array}$ \\
$\begin{array}{l}\text { 7. Se design provides enough room for all users, either standing or seated, } \\
\text { to approach, reach and manipulate. The design provides built in accommodations. }\end{array}$ \\
\hline
\end{tabular}

(Center for Universal Design, 1997). 
Table 2

Principles of Universal Design for learning

\begin{tabular}{ll}
\hline Principle & Description \\
\hline $\begin{array}{l}\text { 1. Multiple means } \\
\text { of engagement }\end{array}$ & $\begin{array}{c}\text { Engagement addresses the affective networks of the brain. Learners must be engaged in } \\
\text { why information is important. When there is motivation to learn new information, } \\
\text { it is more meaningful. Examples of multiple means of engagement include allowing user choice, } \\
\text { pictures and text that are culturally relevant, rewards for learning (credit, recognition), } \\
\text { minimizing distractions (creating routines, customizing workspace and timing), } \\
\text { and providing options for self-regulation (allowing feedback and self-assessment). } \\
\text { Representation addresses the recognition networks of the brain. Learners must be engaged } \\
\text { in what information is important. Each of us has different background, knowledge and abilities. } \\
\text { Having the option to customize information allows a learner to customize her or his learning } \\
\text { experience. Examples of multiple means of representation include options for perception } \\
\text { (like closed captioning, or a translated transcript), providing supports like definitions } \\
\text { and explanatory text, and options for comprehension (background knowledge, } \\
\text { links for more information). } \\
\text { Action and expression address the strategic network of the brain. Learners must be engaged } \\
\text { in how information is important. To make learning strategic and goal-directed, we vary the ways } \\
\text { learners can respond. Examples of multiple means of action and expression include varying the mode } \\
\text { of response (accepting submissions online, print, or verbally), providing options like video } \\
\text { or written response, and options for executive function (like setting one's } \\
\text { own goals and self-monitoring). }\end{array}$ \\
$\begin{array}{l}\text { Multiple means of } \\
\text { action and expression }\end{array}$
\end{tabular}

(CAST, 2018).

the educational arena, these principles also transfer across domains and environments. In fact, UDL can enhance communications and help to improve information sharing across audiences, enabling organizations to better reach their customers, employees, stakeholders, and communities.

UD and UDL principles bring many benefits to the workplace. The Americans with Disabilities Act (ADA, 1990) requires that reasonable accommodations be provided in the workplace for employees with disabilities. A reasonable accommodation is considered:

... any change to the application or hiring process, to the job, to the way the job is done, or to the work environment that allows a person with a disability who is qualified for the job to perform the essential functions of that job and enjoy equal employment opportunities. Accommodations are considered "reasonable" if they do not create an undue hardship or a direct threat. (ADA National Network, n.d.)

However, when we consider the use of UD, some accommodations ultimately may not be needed at all because accessibility has been considered a priority from the start (Sanford, 2016). This does not mean that accommodations in the workplace are not necessary, but rather that, if an environment is highly accessible and user friendly from the starting point, a broader proportion of people will be able to succeed in that environment. In addition, there is no stigma associated with perceived favoritism that might occur if one worker is provided with a particular accommodation while another worker is not.
Indeed, when applying a lens of UD, employers and communities can influence and improve participation of people with disabilities across all facets of society, not just employment. Though the concept of UD is certainly not a new one, it provides an equitable lens to employ across programs and areas of emphasis. As such, UD can provide practical strategies to enhance policies, procedures, and programs that is an equitable approach to help build and sustain a workforce that reflects our population.

\subsection{Benefits of using $U D$}

Throughout history, people have pushed for institutional changes, initiatives, and cultural shifts that have bettered the lives of individuals with disabilities and strengthened the communities they live in. Two movements in the US produced significant changes in services for employment of persons with disabilities. The Civil Rights Movement began in the 1940s and culminated with the Civil Rights Act of 1964, which included Title VII, establishing the Equal Employment Opportunity Commission (EEOC) and prohibiting discrimination in employment. The Disability Rights Movement expanded this initiative with several pieces of legislation including the ADA, which prohibited discrimination in employment, education, public accommodations, transportation, services, and communication. It is the charge of the rehabilitation field to continue the momentum of those who have put in the work before us. Today, one of the greatest opportunities at hand is to expand 
the reaches of UD for employment opportunities. The groundwork has been laid by researchers and practitioners who have come before us and who still work among us (Steinfeld \& Jordana, 2012; Story et al., 1998). Within the context of COVID-19, there is an opportunity for a broader audience to connect with and relate to UD, as employers face new challenges in keeping their employees productive and connected to their jobs. Jobs that may now be done in different settings or with new levels of health and safety requirements.

This is also an opportune time to continue to move forward the academic accomplishments by continuing to further the education on UD principles within the curriculum for pre-professional students in higher education. We have already begun the movement in that direction, through university programs that offer coursework and certificates in UD and that support UD implementation in college courses. This recognizes not only the power of UD but also the need for students across disciplines, including rehabilitation, to have access to the UD principles that can further be embedded in their future careers upon their exit from the higher education system.

Moreover, in the wake of the COVID-19 pandemic and the resulting changes that are likely to be seen in the American workplace and the global economy for many years to come, UD principles are well-situated to address novel needs. UD ensures that employees who are now doing work in different ways, including remote work, are accessing telecommunication technology equitably. Optimizing UD approaches that recognize preferences and needs are available to all people regardless of their disability status can ultimately lead to improved outcomes. There are an array of benefits that arise from a UD approach to employment that include a decreased need for accommodations, lessening the stigma of disability, promoting an inclusive workplace, and improving the overall bottom line of an employer.

\subsubsection{Reduces the need for individualized accommodations}

When environments and systems are built with UD in mind, people with disabilities are less likely to be perceived as posing challenges for professionals to overcome in the workplace. For example, when a person who uses a walker can enter a restaurant independently, using a conveniently located ramp, the hostess does not have to organize several employees to physically assist the person in entering the establishment. Workplace environments that include a variety of accommodations, such as wheelchairaccessible buildings and offices, as well as large print, captioning, and audio capability for all meetings and documents, ensure accessibility for all workers (EARN, 2019).

\subsubsection{Removes stigma of disability}

The concept of UD is one that is accessible and generalizable by its nature. This takes it out of the specific realm of disability and enables broader conversation and understanding about needs and preferences of all people, not just people with disabilities. UD provides another way to discuss issues that affect people with disabilities, but without a need to have disability specific content knowledge. In essence, to use an accessibility metaphor, UD is an on ramp for conversation about inclusivity and workplace access. Additionally, disability stigmas are removed when education and/or experience elevates people with disabilities to positions of equal status in the eyes of professionals and other members of the community. While specific training in disability etiquette and respectful interactions with all persons prepares our workforce to be inclusive of all workers (United Spinal Association, 2015), training and implementation of UD practices within the workplace can be part of those broader educational opportunities that further promote the inclusion of people with disabilities.

\subsubsection{Addresses inclusion of all}

The unique perspectives of each community member enriches our societal shared space. In the workplace, each worker brings unique strengths, which are comprised of various elements such as cultural influence, learning and communication styles, informational discovery, financial contributions, artistic endeavors, perspective building, and civic engagement. By working from an employment model that values inclusion of all in the communal sphere, a community opens itself up to be enriched by a diverse workforce. As a core framework, UD enables and encourages a wider scope of participants to be included as contributors to and consumers of the functions of a community, thereby increasing the vibrancy, health, and potential of each community that employs its tenets. Harrison, Price, and Bell (1998) timelessly described this process as the deep level of diversity that occurs when all people are truly integrated in the workforce. 


\subsubsection{Economic bottom line}

UD also provides an economic advantage to both the employer and employee. Workplace productivity for employees with and without disabilities increases in "universally accessible" environments (National Governor's Association, 2013, p. 7). A recent Accenture study conducted in partnership with the American Association of People with Disabilities (AAPD) and Disability found a positive correlation between employer inclusiveness and financial performance (2018). Highly inclusive companies had higher income, higher profit margins, and higher shareholder returns than did less inclusive companies (Accenture, 2018). In the COVID-19 environment, savvy employers will utilize UD to strengthen the ability of all employees to continue to carry on business as usual in anything but usual times.

\subsection{Strategies for integrating UD principles into VR practice}

Traditionally, supply-side employment models have been the crux of VR practice (Roessler et al., 2018). Many occupations in the VR field emphasize the provision of direct service interventions with consumers (e.g., improving functioning, stamina, and job skills); as such, the training curriculum in rehabilitation counseling has historically centered on understanding the personal experience of disability (e.g., medical and psychosocial aspects) and learning to provide these direct service interventions (e.g., personal adjustment counseling, career counseling, vocational evaluation, case management, supported employment, job seeking skills training; Chan et al., 2010). More recently, however, models that emphasize a holistic conceptualization of disability, accentuating the contextual and environmental factors that determine outcomes, have reaffirmed the need to intervene with environments, not exclusively with consumers.

These models, such as the World Health Organization's (WHO) International Classification of Functioning, Disability, and Health (ICF) and the Illinois Work and Well-Being Model (IW'M) Strauser et al., 2019), describe the limiting roles that environmental barriers in the workplace or in the community play in thwarting the participation of people with disabilities (Chan et al., 2010; Falvo \& Holland, 2018; Rumrill et al., 2020). Further, these limitations reciprocally exacerbate personal factors, such as physical and psychological symptoms (Rumrill et al., 2020). Though provision of accommodations and use of assistive technology can assist in retrofitting an environment to accommodate an individual's functional limitations, it is more cost-effective to proactively implement UD.

Research in the business world continues to affirm the personal and monetary benefits of maintaining a workplace that is universally designed and inclusive of all workers (Frost, 2014; Murphy, 2018; Silveira \& Walters, 2017). Simply creating a "diverse" work environment is not enough to create wholesale change in organizational culture or to translate into tangible increases in worker well-being and productivity. A truly inclusive workplace achieves these positive outcomes by "leveraging awareness, understanding, and appreciation of differences in the workplace to enable individuals, teams, and businesses to perform at their full potential" (Murphy, 2018, p.73). As businesses continue to commit to making individuals with disabilities an emphasis of their inclusion efforts, VR professionals should be prepared with the knowledge and skills to assist employers and collaborate with other professionals in the development of universally designed workplaces in accordance with established UD principles.

Efforts to increase VR professional competencies in UD should begin in the pre-service classroom. Integrating UD into undergraduate and graduate education can be accomplished through a variety of methods, but a comprehensive approach would include integrating UDL strategies into the curriculum, infusing knowledge domains and UD principles into the course content, assessing UD skills through out-of-class assignments, and bringing in professionals from non-VR fields to discuss UD from their own expert perspectives. This begins with modeling UD from the first contact point with students by considering how in-person and online programs can be fully accessible and allow students with and without disabilities to actively engage in training. This includes designing the curriculum to reflect UDL by using multiple means of engagement (e.g., fostering collaboration, using alternative accessible content sources, scaffolding/using frequent assessments, and the instructor being easily accessible), using multiple means of representation (e.g., creating course outcomes that address varying learning preferences, offering real-world experiences, providing choices about product format, and consistently using learning management tools (LMS) and accessible technology), and multiple means of expression (e.g., utilizing conceptual mapping tools and/or summative assessments, providing opportunities to practice 
with supports, providing choices when responding, and offering flexible opportunities for demonstrating skills; Boothe et al., 2018).

As prospective VR professionals complete their training or degree programs, they should be prepared to demonstrate competencies in the field by integrating UDL into any skill- or education-based program or intervention for their consumers. They should also be prepared to apply UD and UDL principles in consultation services to employers and other stakeholders to make workplaces and community environments inclusive and accessible for all. VR professionals often collaborate with a variety of employment and healthcare professionals (e.g., human resource managers, counselors, social workers, OTs, PTs, nurses, doctors, etc.), but it is also important to build collaborative relationships with UD professionals such as architects, designers, assistive technology practitioners, human factors engineers, and web accessibility specialists. VR professionals, with knowledge of medical and psychosocial aspects of disability, job analysis, and how to devise and implement accommodation plans, can serve as valuable resources in an integrative team to both advocate for and help implement UD with the goal in mind of attracting and retaining more workers with disabilities.

In practice, UD constitutes a shift from a reactive process of using accommodations to make a workspace accessible to a proactive process of designing workspaces to utilize workers' talents regardless of limitation. To achieve this end, VR professionals must have "space" in professional practice to work with employers on such proactive solutions, requiring public and private VR agencies to re-evaluate workloads and equally prioritize proactive approaches like assisting in UD within the VR professional's job duties. Providing UD services to employers can occur across multiple levels, including:

- The physical work environment (e.g., effective lighting, space for travel and maneuvering, minimal noise levels, color contrast in walkways to help with wayfinding);

- Workplace technologies and tools (e.g., captioning, speech to text software, machines that can be fully operated without visual cues, providing access to cognitive support technology); and

- Within-work policies, communications, and safety processes (e.g., multi-sensory alarm signals, high contrast signage, clearly identified and placed emergency equipment, reflecting respect for all employees within policies and procedures; NWADA Center, 2020).

VR professionals can assist in ensuring that individuals with disabilities are consulted and utilized in the UD planning process, and, once implemented, that the effectiveness of the UD is periodically assessed with a plan put in place to implement future accommodations if necessary (Burgstahler, 2015).

As has been demonstrated in numerous studies, the application of UD principles in the workplace improves access for all workers and deepens connections among diverse employees, thus leading to greater productivity. The seven principles of UD offer concrete suggestions for ways to implement greater access for persons with disabilities in the workplace (Center for Universal Design, 1997). The principles address access to employment facilities through equitable use, low physical effort to enter and use, and consideration of size and space for use. VR professionals can advocate for workplace facilities that have ready access for all employees with furniture and space to accommodate the needs of all. The seven principles also address access to materials through flexibility of use, intuitive use, readily perceptible information, and higher tolerance for error in use of materials, in conjunction with the principles of UDL. VR professionals can advocate for these principles by encouraging employers to use materials and equipment that are designed for use by all persons, with multiple modalities for use such as captioning, visual contrast, and basic reading levels. By employing the strategies outlined in the preceding section, VR professionals can maximize the contributions of persons with disabilities in the workforce and increase productivity for all workers.

\section{Conclusion}

The benefits of UD reach far beyond accessibility of a limited number of people with disabilities. Indeed, improving access to spaces, systems, interactions, and resources paves the way for more inclusive workforces that benefit employers by tapping into a wider network of employees, consultants, stakeholders, and customers. By creating workplaces that are universally designed, employers facilitate access to the knowledge, skills, and creativity of a more diverse pool of participants. The result is improved productivity by all workers and increased access for consumers of products and services. The urgency of this matter 
is further illustrated in the new realities of COVID19 in the workplace, where UD strategies can help all workers succeed in new physical and virtual realities. VR professionals have an important role to play by helping employers and workers with disabilities understand and implement the core principles of UD and facilitate the movement toward more productive workplace environments for all.

\section{Conflict of interest}

None to report.

\section{Funding}

This research was supported in part by a grant by the United States Department of Labor, Office of Disability Employment Policy in the amount of $\$ 3,500,000$ under Cooperative Agreement No. OD-32548-18-75.4.21. This document does not necessarily reflect the views or policies of the U.S. Department of Labor, nor does mention of trade names, commercial products, or organizations imply endorsement by the U.S. Government.

\section{References}

Accenture. (2018). Getting to equal: The disability inclusion advantage. Author. Retrieved from: https://www.accenture. com/_acnmedia/pdf-89/accenture-disability-inclusionresearch report.pdf

Americans With Disabilities Act of 1990, Pub. L. No. 101-336, 104 Stat. 328 (1990).

Baio, J., Wiggins, L., Christensen, D. L., et al. (2018). Prevalence of autism spectrum disorder among children aged 8 years - Autism and Developmental Disabilities Monitoring Network, 11 Sites, United States, 2015. MMWR Surveillance Summary, 67(No.SS-6):1-23. doi: http://dx.doi. org/10.15585/mmwr.ss6706a1external.icon

Burgstahler, S. (2015). Universal design: Process, principles, and applications. DO-IT, University of Washington. https://www.washington.edu/doit/universal-design-processprinciples-and-applications

Boothe, K. A., Lohmann, M. J., Donnell, K. A., \& Hall, D. D. (2018). Applying the principles of universal design for learning (UDL) in the college classroom. Journal of Special Education Apprenticeship, 7(3), n3.

CAST (2018). Universal design for learning guidelines version 2.2. Retrieved from http://udlguidelines.cast.org

Center for Universal Design, (1997). The principles of universal design (Version 2.0). NC State University, Author.

Chan, F., Strauser, D., Gervey, R., \& Lee, E. J. (2010). Introduction to demand-side factors related to employment of people with disabilities. Journal of Occupational Rehabilitation, 20(4), 407-411. https://doi.org/10.1007/s10926-010-9243-7.
Charlton, J. I. (1998). Nothing about us without us: Disability oppression and empowerment. University of California Press.

Cichy, K., Leslie, M., Rumrill, P., \& Koch, L. (2017). The implications of population aging and the relationship between aging and disability for vocational rehabilitation practice. Journal of Vocational Rehabilitation, 47(2), 185-196. https://doi.org/10.3233/JVR-170894

Civil Rights Act of 1964 §7, 42 U.S.C. §2000e et seq (1964).

Employer Assistance and Resource Network on Disability Inclusion (EARN, 2019). Increasing disability inclusion: Centralized accommodation programs as a best practice. Retrieved from https://askearn.org/training-center/webinars/centralizedaccommodation-programs-as-a-best-practice/

Falvo, D., \& Holland, B. (2018). Medical and psychosocial aspects of chronic illness and disability (6th ed.). Jones and Bartlett Learning.

Fill, M.-M. A., Miller, A. M., Wilkinson, R. H., Warren, M. D., Dunn, J. R., Schaffner, W., \& Jones, T. F. (2018). Educational disabilities among children born with neonatal abstinence syndrome. Pediatrics, 142(3). https://doi.org/ 10.1542/peds.2018-0562

Frost, S. (2014). The inclusion imperative: How real inclusion creates better business and builds better societies. http://www.tinyurl.com/y3unosvu

Harrison, D. A., Price, K. H., \& Bell, M. P. (1998). Beyond relational demography: Time and the effects of surface- and deep-level diversity on work group cohesion. Academy of Management Journal, 41, 96-107. https://doi.org/10.5465/256901

Koch, L., \& Rumrill, P. (2017). Medical, psychosocial, and vocational aspects of emerging disabilities for rehabilitation counselors (2nd ed.). Springer.

Kraus, L., Lauer, E., Coleman, R., \& Houtenville, A. (2018). 2017 Disability statistics annual report. University of New Hampshire.

McLaughlin, M. E., Bell, M. P., \& Stringer, D. Y. (2004). Stigma and acceptance of persons with disabilities: Understudied aspects of workforce diversity. Group \& Organization Management, 29(3), 302-333. https://doi.org/10.1177/ 1059601103257410

Murphy, W. (2018). Distinguishing diversity from inclusion in the workplace: Legal necessity or common sense conclusion? Journal of Business Diversity, 18(4), 65-83. https://doi.org/ 10.33423/jbd.v18i4.247

National Governor's Association. (2013). A better bottom line. Employing people with disabilities. Author. https://askearn. org/wp-content/uploads/docs/nga_2013_better_bottom_line.pdf

Northwest ADA (NWADA) Center. (2020). Universal design in the workplace. http://nwadacenter.org/factsheet/universal-designworkplace

Roessler, R., Rubin, S., \& Rumrill, P. (2018). Case management and rehabilitation counseling (5th ed.). Pro-Ed.

Rumrill, P. D., Strauser, D. R., Greco, C., Rumrill, S. P., \& Sheppard-Jones, K. (2020). The Illinois Work and Well-Being Model: An intervention framework to improve employment and health outcomes for stroke survivors. Journal of Vocational Rehabilitation, 52(2), 195-204. https://doi.org/10.3233/JVR191069

Rutter, M. (2005), Incidence of autism spectrum disorders: Changes over time and their meaning. Acta Padiatrica, 94, 2-15. https://doi.org/10.1111/j.1651-2227.2005.tb01779.x

Silveira, E., \& Walters, J. (2017). Building blocks of workplace inclusion. The Association for Talent Development. 
Steinfeld, E., \& Jordana, M. (Eds.). (2012). Universal design: creating Inclusive environments. Wiley Publishing Company.

Strauser, D., Rumrill, P., \& Greco, C. (2019). Applying the Illinois Work and Well-Being Model to increase labor force participation among people with multiple sclerosis. Journal of Vocational Rehabilitation, 51(1), 11-20. https://doi. org/10.3233/JVR-191021
Substance Abuse and Mental Health Services Administration. (2015). Federal Guidelines for Opioid Treatment Programs. HHS Publication No. Rockville, MD: Substance Abuse and Mental Health Services Administration.

United Spinal Association. (2015). Disability etiquette: Tips on interacting with people with disabilities. http://www. unitedspinal.org/pdf/DisabilityEtiquette.pdf 